\title{
Editorial: Sea Ice: Bridging Spatial-Temporal Scales and Disciplines
}

\author{
Benjamin A. Lange ${ }^{1 *}$, Hauke Flores ${ }^{2}$, Jeff S. Bowman ${ }^{3}$, Janne-Markus Rintala ${ }^{4}$ and \\ Giulia Castellani² \\ ${ }^{1}$ Norwegian Polar Institute, Fram Centre, Tromsø, Norway, ${ }^{2}$ Alfred-Wegener-Institute Helmholtz Center for Polar and Marine \\ Research, Bremerhaven, Germany, ${ }^{3}$ Scripps Institution of Oceanography, University of California, San Diego, San Diego, CA, \\ United States, ${ }^{4}$ INAR -Institute for Atmospheric and Earth System Research, University of Helsinki, Helsinki, Finland
}

Keywords: Arctic Ocean, Southern Ocean, remote sensing, sea ice algae, interdisciplinary, polar regions, biogeochemistry, cryosphere

\section{Editorial on the Research Topic}

\section{Sea Ice: Bridging Spatial-Temporal Scales and Disciplines}

The ice-covered Arctic Ocean has undergone rapid changes, including pronounced sea ice thinning and volume loss, a rapidly declining sea ice extent and a shift toward a seasonally dominated ice cover (Kwok, 2018; Stroeve and Notz, 2018). In the Southern Ocean, there is large regional and interannual variability in sea ice extent (Parkinson and Cavalieri, 2012; Holland et al., 2017). Although there has been an overall slightly increasing trend in Antarctic sea ice extent, some regions have experienced drastic changes comparable to the Arctic (Stammerjohn et al., 2012; Hobbs et al., 2016). Yet the impact of these strong changes in sea ice habitat properties on polar marine ecosystems is not fully understood (Gerland et al., 2019; IPCC, 2019).

Innovative technologies, improved methods and novel experimental approaches increase the

Edited and reviewed by: Regine Hock University of Alaska Fairbanks, United States

*Correspondence: Benjamin A. Lange blange.sea.ice@gmail.com

Specialty section

This article was submitted to Cryospheric Sciences, a section of the journal Frontiers in Earth Science

Received: 17 March 2020 Accepted: 30 March 2020 Published: 29 April 2020

Citation:

Lange BA, Flores H, Bowman JS, Rintala J-M and Castellani G (2020) Editorial: Sea Ice: Bridging

Spatial-Temporal Scales and Disciplines. Front. Earth Sci. 8:119. doi: 10.3389/feart.2020.00119 reliability and accuracy of observations while at the same time enable us to bridge multiple spatial-temporal scales across disciplines in logistically challenging environments. In combination with remote sensing and numerical models of sea-ice ecosystems, an increasingly comprehensive understanding of biogeochemical processes and interaction of ice-associated organisms with the sea ice environment can be scaled in time and space. Further development and the integration of these various approaches and technologies across disciplines will solidify predictions of the impact of changing sea ice habitats on biodiversity and ecosystem functions.

In this Research Topic we focused on field-based research, modeling studies and laboratorybased experiments, which provided novel approaches, innovative technologies, and/or new interdisciplinary perspectives to sea ice research.

Campbell et al. investigated ice algal photophysiology from ${ }^{14} \mathrm{C}$ incubations of sea ice samples prepared by three different melt procedures. They extended their experimental investigation using a common sea ice diatom $N$. frigida as a model organism. Observed large differences in several photophysiological parameters were related to relative changes in salinity resulting from the different melt procedures. Thus, the approach chosen to melt ice samples almost certainly contributed to the variability in production reported across polar regions.

Janssens et al. conducted the first laboratory-controlled sea-ice growth experiment, with trace metal clean conditions, to investigate the role of organic matter in incorporating iron into sea ice. They showed that biogenic particulate iron was preferentially incorporated into sea ice compared to lithogenic particulate iron and that the incorporation of dissolved iron is favored by the presence of organic ligands. 
König et al. present controlled laboratory experiments which investigated the dynamics of the total inorganic carbon budget (TIC) in an experimental seawater tank. Their experiment showed that the bulk of the TIC remained in the under-ice water rather than in the newly formed sea ice. König et al. conclude that brine drainage is a key process transporting inorganic carbon into the surface water during ice formation.

Kauko et al. followed the ice algal species succession in young Arctic sea ice during spring. They showed that the seeding source varied between algal groups, with dinoflagellates originating from the water column and diatoms from the surrounding older ice. Their results provide further evidence that the surrounding ice is an important seeding source, particularly over deep oceanic regions and in early spring when water column algal biomass is low. The successional patterns evolved into ice-associated algae independent of environmental conditions, which highlights the importance of biological traits in the colonization of the sea ice environment.

Limoges et al. investigated the dynamics of the paleooceanographic sea-ice marker IP25 in relation to ice algae community structure both in sea ice and in sediments from Young Sound, Greenland. They showed that only three rare species of sea-ice diatoms produced IP25, causing only limited concentrations of the biomarker in both sea ice and sediments. The ice algae community changed between freezing and melting conditions, and the melt- and post-melt algae assemblages dominated in the sediment. The results of this study demonstrate that concentrations of IP25 in seafloor sediments largely depend on the productivity of sea-ice diatoms.

Uhlig et al. investigated concentrations of Dimethylsulfide (DMS) and its precursor Dimethylsulfonioproprionate (DMSP) in relation to sea-ice exposure and hydrographic properties. In Atlantic-influenced open waters DMS concentrations were higher and positively correlated with DMSP concentrations and chlorophyll concentration, whereas in polar- and sea ice-influenced waters DMS and DMSP concentrations were low, showing no relationship between the two compounds or chlorophyll. This indicates decoupling of DMSP production from microbial conversion to DMS, suggesting that DMS production in the ice-covered Central Arctic Ocean is lower than expected from DMSP concentrations or phytoplankton biomass.

Forrest et al. deployed an AUV fitted with multispectral sensors to remotely estimate ice-algal biomass along $\sim 500 \mathrm{~m}$ transects beneath land-fast sea ice in McMurdo Sound, Antarctica. Bio-optical algorithms developed using local measurements explained $40 \%$ of the biomass variability. The poor performance of the algorithm was attributed to difference in footprint size of the optical sensor compared to ice core samples. Nevertheless, their results support continued development of bottom-ice biophysical remote sensing techniques.

König et al. provided an evaluation of five currently available atmospheric correction processors (ACOLITE, ATCOR, iCOR, Polymer, and Sen2Cor) for Sentinel-2 multispectral observations using in situ spectral measurements over snow, sea ice and open water. They showed that Polymer performed best over open water while ACOLITE, ATCOR and iCOR performed well over sea ice. ATCOR, iCOR, and Sen2Cor failed in retrieval of aerosol optical thickness and water vapor while ACOLITE was within the range of uncertainty for these parameters. They conclude that the choice of correction processor can have a large influence on secondary products.

Steiner et al. integrate scientific methods with indigenous knowledge by synthesizing results from models, observations and laboratory experiments in order to better understand current and future changes to Arctic marine ecosystems, how these changes impact society and how can we better manage and plan for climate change. They focus on a key forage species in the Arctic Ocean, Arctic cod (Boreogadus saida). Their model simulations showed a $17 \%$ decrease in Arctic cod populations over the next 80 years as a result of migration limits and temperature increases. Furthermore, they highlight the need for more extensive, unified community- and science-based monitoring programs to improve knowledge-based management and planning.

Logistical difficulties will undoubtedly remain as some of the largest hurdles in polar research. Nevertheless, we should continue to strive for improved spatial and temporal coverage of observations and monitoring programs throughout both polar regions. There remain large geographical and seasonal knowledge gaps in sea ice related research, such as observations within the central Arctic Ocean, year-long observation and monitoring programs and winter studies (e.g., MOSAiC, Nansen Legacy, among others). Satellite and airborne remote sensing have provided unprecedented detail of the snow and ice physical properties, but as of yet still cannot penetrate the snow and ice matrix to observe the under-ice habitat, making ecologically relevant observations of polar marine environments nearly impossible from air/space. Improving our understanding of sea ice biogeochemical processes and biophysical linkages can foster rapid improvements in our understanding of projected changes in polar marine environments through approaches that couple experimental results, observations and models at different spatial and temporal scales.

\section{AUTHOR CONTRIBUTIONS}

BL coordinated the writing of the editorial. BL and HF made original plans for the Research Topic and edited several published papers in this Research Topic. JB, J-MR, and GC provided substantial input for the initial submitted Research Topic proposal, edited manuscripts, and commented on the editorial.

\section{FUNDING}

BL, HF, and GC were supported by the Alfred-Wegener-Institute Helmholtz Center for Polar and Marine Research and funding from the Helmholtz Association Young Investigators Group Iceflux: Ice ecosystem carbon flux in polar oceans (VH-NG-800). BL was also supported by a Visiting Fellowship from the Natural Science and Engineering Research Council of Canada (NSERC) supported by Fisheries and Oceans Canada International Governance Strategy, in addition to current support from NPI and funding from the Research Council of Norway (CAATEX [280531] and HAVOC [280292]). GC was currently supported 
by the EcoLight project (grant number 03V01465), part of the Changing Arctic Ocean program, jointly funded by the UKRI Natural Environment Research Council (NERC) and the German Federal Ministry of Education and Research

\section{REFERENCES}

Gerland, S., Barber, S., Meier, W., Mundy, C. J., Holland, M., Kern, S., et al. (2019). Essential gaps in the understanding of the roles and functions of Arctic sea ice. Environ. Res. Lett. 14:043002. doi: 10.1088/1748-9326/ab09b3

Hobbs, W. R., Massom, R., Stammerjohn, S., Reid, P., Williams, G., and Meier, W. (2016). A review of recent changes in Southern Ocean sea ice, their drivers and forcings. Global. Planet. Change 143, 228-250. doi: 10.1016/j.gloplacha.2016.06.008

Holland, M. M., Landrum, L., Raphael, M., and Stammerjohn, S. (2017). Springtime winds drive Ross Sea ice variability and change in the following autumn. Nat. Commun. 8:731. doi: 10.1038/s41467-017-00820-0

IPCC (2019). IPCC Special Report on the Ocean and Cryosphere in a Changing Climate, eds H.-O. Pörtner, D. C. Roberts, V. Masson-Delmotte, P. Zhai, M. Tignor, E. Poloczanska, K. Mintenbeck, A. Alegría, M. Nicolai, A. Okem, J. Petzold, B. Rama, and N. M. Weyer. Available online at: https://www.ipcc.ch/ site/assets/uploads/sites/3/2019/12/SROCC_FullReport_FINAL.pdf

Kwok, R. (2018). Arctic sea ice thickness, volume, and multiyear ice coverage: losses and coupled variability (1958-2018). Environ. Res. Lett. 13:105005. doi: $10.1088 / 1748-9326 /$ aae3ec
(BMBF). JB was supported through the National Science Foundation (NSF-OPP 1821911, NSF-OPP 1846387), and by an Early Career Marine Microbial Investigator award from these Simons Foundation.
Parkinson, C. L., and Cavalieri, D. J. (2012). Antarctic sea ice variability and trends, 1979-2010. Cryosphere 6, 871-880. doi: 10.5194/tc-6871-2012

Stammerjohn, S., Massom, R., Rind, D., and Martinson, D. (2012). Regions of rapid sea ice change: an inter-hemispheric seasonal comparison. Geophys. Res. Lett 39:L06501. doi: 10.1029/2012GL050874

Stroeve, J., and Notz, D. (2018). Changing state of Arctic sea ice across all seasons. Environ. Res. Lett. 13:103001. doi: 10.1088/1748-9326/aade56

Conflict of Interest: The authors declare that the research was conducted in the absence of any commercial or financial relationships that could be construed as a potential conflict of interest.

Copyright (c) 2020 Lange, Flores, Bowman, Rintala and Castellani. This is an openaccess article distributed under the terms of the Creative Commons Attribution License (CC BY). The use, distribution or reproduction in other forums is permitted, provided the original author(s) and the copyright owner(s) are credited and that the original publication in this journal is cited, in accordance with accepted academic practice. No use, distribution or reproduction is permitted which does not comply with these terms. 